\title{
Erratum to: tDCS application over the STG improves the ability to recognize and appreciate elements involved in humor processing
}

\author{
Mirella Manfredi $^{1} \cdot$ Alice Mado Proverbio $^{2} \cdot$ Ana Paula Gonçalves Donate ${ }^{1}$. \\ Sofia Macarini Gonçalves Vieira ${ }^{1} \cdot$ William Edgar Comfort ${ }^{1}$. \\ Mariana De Araújo Andreoli ${ }^{1}$ Paulo Sérgio Boggio ${ }^{1}$
}

Published online: 18 May 2017

(C) Springer-Verlag Berlin Heidelberg 2017

\section{Erratum to: Exp Brain Res \\ DOI 10.1007/s00221-017-4932-5}

The original version of this article contained an error in two references (listed below) for Bonda et al. (1996).

Bonda E, Ostry D, Evans A (1996a) Specific involvement of human parietal systems in the perception of biological motion and the amygdala. J Neurosci 76(11):3737-3744

Bonda E, Petrides M, Ostry D, Evans A (1996b) Specific involvement of human parietal systems and the amygdala in the perception of biological motion. J Neurosci 16:3737-3744

They should be deleted and substituted with just one paper whose the correct reference is:
Bonda E, Petrides M, Ostry D, Evans A (1996) Specific involvement of human parietal systems and the amygdala in the perception of biological motion. J Neurosci 16(11):3737-3744

The online version of the original article can be found under doi: 10.1007/s00221-017-4932-5.

Mirella Manfredi

mirella.manfredi@gmail.com

1 Social and Cognitive Neuroscience Laboratory and Developmental Disorders Program, Center for Health and Biological Sciences, Mackenzie Presbyterian University, Rua Piaui, 181, São Paulo 01241-001, Brazil

2 Department of Psychology, University of Milano-Bicocca, Milan, Italy 